\title{
Tratamento cirúrgico de abscesso odontogênico em nível hospitalar
}

\author{
Surgical treatment of odontogenic abscess at hospital level \\ Tratamiento quirúrgico del absceso odontogénico a nivel hospitalario \\ Leonardo Perez FAVERANI ${ }^{\mathbf{1}}$ \\ Gabriel Ramalho FERREIRA ${ }^{2}$ \\ Idelmo Rangel GARCIA JUNIOR ${ }^{1}$ \\ Francisley Avila SOUZA ${ }^{1}$ \\ Gabriela Marian Flud IBRAHIM ${ }^{3}$ \\ Ellen Cristina GAETTI JARDIM ${ }^{4}$ \\ ${ }^{\prime}$ Docente. UNESP Univ Estadual Paulista, Faculdade de Odontologia de Araçatuba, Departamento de Diagnóstico e Cirurgia 16015-050 Araçatuba-SP, Brasil \\ ${ }^{2}$ Cirurgião Bucomaxilofacial no Hospital de Reabilitação de Anomalias Craniofaciais - USP \\ ${ }^{3}$ Curso de Graduação em Odontologia, UFMS Universidade Federal do Mato Grosso do Sul, Faculdade de Odontologia FAODO 79070-900 Campo Grande-MS, Brasil \\ ${ }^{4}$ Docente. UFMS Universidade Federal do Mato Grosso do Sul, Faculdade de Odontologia FAODO 79070-900 Campo Grande-MS, Brasil
}

\section{Resumo}

A infecção odontogênica é um grave problema de saúde pública. O atendimento hospitalar fica basicamente direcionado a atenção aos casos mais graves que requerem tratamento imediato de antibioticoterapia endovenosa bem como remoção urgente da causa. Sendo assim, o objetivo é apresentar um caso de paciente de 43 anos de idade, sexo feminino, queixando-se de dor em região de dente 24 com aumento volumétrico evidente assim como drenagem espontânea de exsudato via sulco gengival. O tratamento após exames complementares de rotina foi a exodontia do elemento dentário sob anestesia local em atenção hospitalar associado a drenagem da coleção purulenta. Após eliminação da causa bem como a drenagem, 48 horas destas a paciente recebeu alta hospitalar com retorno programado. Segue sem queixas e sem outras afecções semelhantes.

Descritores: Abscesso Periapical; Cirurgia; Terapêutica.

\section{Abstract}

Odontogenic infection is a serious public health problem. Hospital care is basically directed to the attention to the most severe cases that require immediate treatment of intravenous antibiotic therapy as well as urgent removal of the cause. Thus, the objective is to present a case of a 43-year-old female patient complaining of pain in the tooth region 24 with evident volumetric increase as well as spontaneous drainage of exudate via the gingival sulcus. Treatment after routine complementary examinations was dental element extraction under local anesthesia in hospital care associated with drainage of the purulent collection. After elimination of the cause as well as drainage, 48 hours after this the patient was discharged with scheduled return. It follows no complaints and no other similar conditions.

Descriptors: Periapical Abscess; Surgery; Therapy.

\section{Resumen}

La infección odontogénica es un grave problema de salud pública. La atención hospitalaria se dirige básicamente a la atención de los casos más graves que requieren tratamiento inmediato de antibióticos por vía intravenosa, así como la eliminación urgente de la causa. Por lo tanto, el objetivo es presentar un caso de una paciente de 43 años que se queja de dolor en la región dental 24 con un aumento volumétrico evidente, así como un drenaje espontáneo de exudado a través del surco gingival. El tratamiento después de los exámenes complementarios de rutina fue la extracción del elemento dental bajo anestesia local en la atención hospitalaria asociada con el drenaje de la colección purulenta. Después de la eliminación de la causa y el drenaje, 48 horas después, el paciente fue dado de alta con un retorno programado. Sigue sin quejas y no otras condiciones similares.

Descriptores: Absceso Periapical; Cirugía; Terapéutica.

\section{INTRODUÇÃO}

As infecções odontogênicas são patologias de origem dentária que podem advir de diferentes origens tais como periapical, proveniente de cáries que causam necrose pulpar e se disseminam para o tecido periapical; ou periodontal, decorrente de uma infecção bacteriana de uma bolsa periodontal que possibilita a inoculação da bactéria nos tecidos moles subjacentes, ou também de origem pericoronária, quando o dente semi-incluso apresenta infecção ao redor do seu capuz periocoronário ${ }^{1}$.

Sendo assim, a fim de realizar o diagnóstico de infecção odontogênica, é necessário saber as principais características clínicas associadas os conhecidos sinais flogísticos do processo inflamatório tais como, dor, edema, calor, rubor, perda de função (trismo, disfagia, dispnéia), febre bem como assimetria facial ${ }^{2}$.

Associado a isso, como exames complementares para o diagnóstico, podem ser realizados os exames panorâmico e periapical, as quais podem apresentar uma imagem radiolúcida mal definida. Ou mesmo, pode-se realizar uma tomografia computadorizada ${ }^{3}$ exame mais específico e de maior capacidade de auxílio diagnóstico em graves infecções ${ }^{4}$ que acometem os espaços fasciais associando sempre aos exames laboratoriais. Diante do exame clínico e dos exames complementares, é possível realizar o diagnóstico de infecção odontogênica e direcionar para um tratamento adequado que compreenderá a drenagem cirúrgica da infecção, a antibioticoterapia adequada a cada caso e a remoção urgente da causa.

Deste modo, o presente trabalho tem como objetivo relatar um caso clínico de uma paciente com infecção odontogênica com extensão orbitária que procurou atendimento da cirurgia e traumatologia bucomaxilofacial em ambiente hospitalar.

\section{CASO CLÍNICO}

Paciente do sexo feminino, 43 anos de idade, leucoderma, foi admitido na Santa Casa de Araçatuba (SP) pela equipe de Cirurgia e Traumatologia Bucomaxilofacial, com quadro de infecção de origem odontogênica com extensão orbitária. Na anamnese relatou não apresentar comorbidades sistêmicas nem vícios ou hábitos deletérios.

Ao exame clínico apresentou assimetria facial importante à custa de edema $(+2 /+4)$ em terço médio de face à esquerda com extensão periorbitária ipsilateral causando oclusão palpebral do mesmo 
lado, além de hiperemia na região, de consistência amolecida e com dor à palpação sem precisar com exatidão o tempo de evolução (Figura 1).

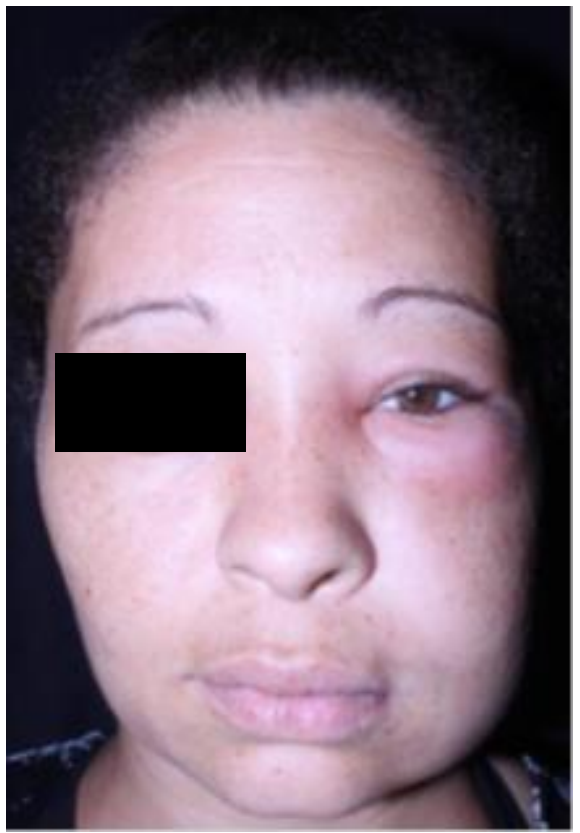

Figura 1: Paciente com importante edema em terço médio de face a esquerda com oclusão pálpebra a esquerda.

Ao exame intraoral a mesma apresentou tumefação e drenagem espontânea de coleção purulenta via sulco em região do dente 24 (primeiro pré-molar superior do lado esquerdo). Foi realizada tomografia computadorizada imediata a entrada hospitalar e evidenciando imagens hipoatenuantes em seio maxilar a esquerda (Figuras 2A e 2B) confirmando o quadro infeccioso de origem odontogênica.

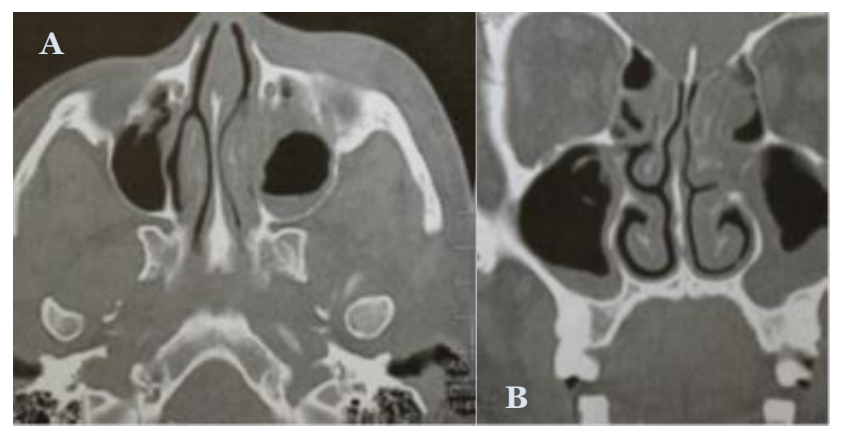

Figura 2: A e B. Cortes axial e coronal de uma tomografia computadorizada demonstrando o velamento importante da região de seio maxilar a esquerda.

Confirmando o diagnóstico, o tratamento clínico da paciente consistiu de cobertura antibiótica intravenosa de amplo espectro com cefalotina (500 $\mathrm{mg}$ a cada 6 horas), e metronizadol (400 $\mathrm{mg}$ a cada 8 horas), analgésico (Dipirona sódica 500mg a cada 6 horas), antiinflamatório esteroidal (10 mg de dexametasona a cada 12 horas por dois dias); hidratação com soro fisiológico $0,9 \%$ e bochecho com clorexidina $0,12 \%$ duas vezes ao dia. Posteriormente, a paciente foi submetida a drenagem intrabucal e colocação de dreno de Penrose e remoção do dente envolvido (24). (Figuras 3 a 5).

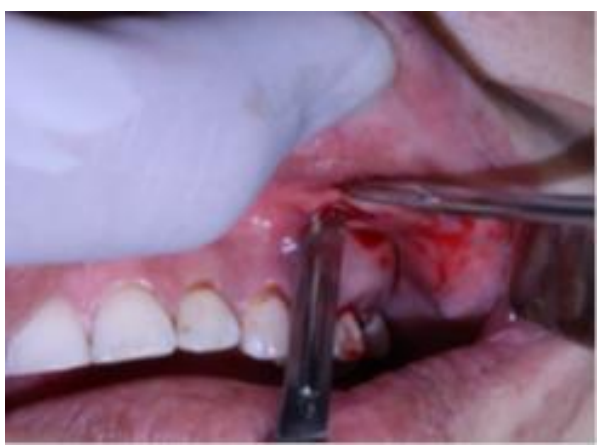

Figura 3: A. Incisão em fundo de vestíbulo.

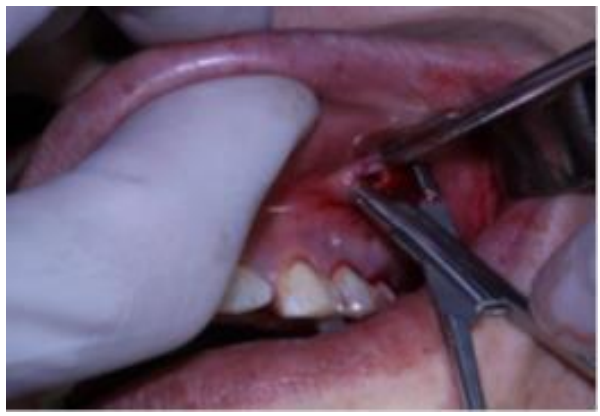

Figura 4. Diérese com instrumental rombo.

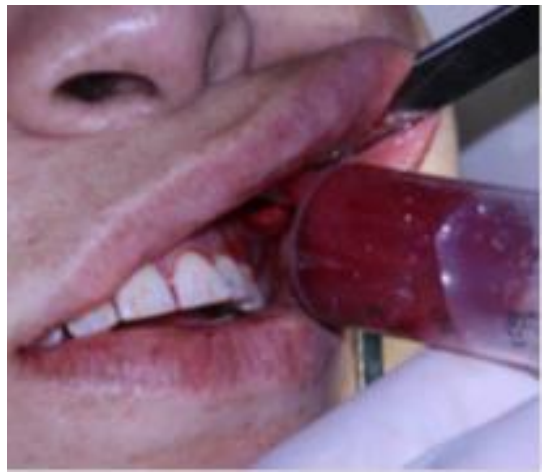

Figura 5. Punção na região do dente envolvido.

Melhora clinica foi evidente com 24 horas pós-procedimentos, 48 horas do mesmo, remissão completa da sintomatologia e a paciente teve alta três dias após internação com prescrição de cefalexina $500 \mathrm{mg}$ a cada 8 horas por 7 dias associada ao metronidazol $500 \mathrm{mg}$ a cada 8 horas via oral por 7 dias. Após a terapia medicamentosa, a paciente não apresentou mais sintomatologia nem tampouco queixas.

\section{DISCUSSÃO}

A infecção odontogênica configura verdadeiro problema de saúde pública ${ }^{5}$ uma vez que requer $\mathrm{o}$ atendimento especializado, recursos materiais bem como por vezes a necessidade de atenção hospitalar como evidenciado no caso apresentado.

Em infecções dentárias que acometem a região da maxila, sobretudo posterior, em virtude da proximidade com o seio maxilar pode postergar a observação do quadro infeccioso. A paciente apresentava aumento volumétrico evidente com oclusão de pálpebra e sintomatologia dolorosa sem precisar exatamente o início da mesma.

Desta feita, em virtude disso a disseminação 
do quadro infeccioso em elementos maxilares pode gerar em virtude de uma infecção outrora restrita ao ápice dentário levando a sinusites maxilares, órbita e trombose do seio cavernoso bem como infecções cerebrais como apontado por Manor et al. ${ }^{6}$

Uma vez feito o diagnóstico o plano de tratamento deve ser rapidamente instituído ${ }^{7}$ e consiste na eliminação rápida do foco de infecção bem como a antibioticoterapia adequada, hidratação e suporte ao paciente $^{8}$. A paciente acima recebeu a medicação condizente com o quadro apresentado, cefalosporinas de primeira geração associada ao metronidazol cumprem muito bem a cobertura contra as bactérias comumente encontrada nesse tipo de situação (bactérias Gram +, Gram - como anaeróbios) e com isso a rápida remissão da afecção após a eliminação do foco causador.

Deste modo, é de extrema importância o diagnóstico e o plano de tratamento adequado para cada caso. A paciente descrita já apresentava exsudato purulento drenado espontaneamente na cavidade bucal sendo que se o tratamento prévio tivesse sido feito nos primeiros momentos da presença da sintomatologia dolorosa a exodontia do referido dente poderia ter sido evitada.

\section{CONSIDERAÇÕES FINAIS}

A partir do caso clinico apresentado pode-se concluir, a infecção odontogênica requer um tratamento urgente e a remoção da causa associada a antibioticoterapia e o diagnóstico correto foi essencial para a resolução rápida do caso.

\section{REFERÊNCIAS}

1. Mardini S, Gohel A. Imaging of Odontogenic Infections. Radiol Clin North Am. 2018; 56(1):31-44.

2. DeAngelis AF, Barrowman RA, Harrod R, Nastri AL. Review article: Maxillofacial emergencies: oral pain and odontogenic infections. Emerg Med Australas. 2014;26(4):336-42.

3. Vasconcelos BEC, Cauás M, Albert DGM, Nascimento GJF, Holanda GZ. Disseminação de infecção odontogênica através das fáscias cervicais profundas: relato de caso clínico. Rev Cir Traumat Bucomaxilofac. 2002;2(1):21- 25.

4. Ramos S, Ramos RF, Ramos HF, Ramos BF. O Uso da Tomografia Computadorizada no Diagnóstico do Abscesso Peritonsilar Arq Int. Otorrinolaringol/Intl Arch Otorhinolaryngol. 2006;10(1):67-70.

5. Wang J, Ahani A, Pogrel MA. A five-year retrospective study of odontogenic maxillofacial infections in a large urban public hospital. Int $\mathbf{J}$ Oral Maxillofac Surg. 2005;34(6):646-49.

6. Manor Y, Garfunkel AA. Brain abscess following dental implant placement via crestal sinus lift - a case report. Eur J Oral Implantol. 2018; 11(1):113-17.

7. Lima FGGP, Rios LGC, Cunha LTMQ, Rocha LF, Batista JD. Abordagem clínico-cirúrgica de infecção complexa em região maxilo-facial: relato de caso. Rev Odontol Bras Central. 2018;27(81): 112-16.

8. Jundt JS, Gutta R. Characteristics and cost impact of severe odontogenic infections. Oral Surg Oral Med Oral Pathol Oral Radiol. 2012;114(5):558-66.

\section{CONFLITO DE INTERESSES}

Os autores declaram não haver conflitos de interesse.

\section{AUTOR PARA CORRESPONDÊNCIA}

\section{Ellen Cristina Gaetti Jardim}

Cidade Universitária, Av. Costa e Silva - Pioneiros 79070-900 Campo Grande - MS, Brasil

Telefone: (67) 3345-7001

email: ellen.jardim@ufms.br
Submetido em 16/07/2019

Aceito em 20/04/2020 